\title{
Review Article \\ The Review of GRACE Data Applications in Terrestrial Hydrology Monitoring
}

\author{
Dong Jiang, ${ }^{1}$ Jianhua Wang, ${ }^{2}$ Yaohuan Huang, \\ Kang Zhou, ${ }^{3}$ Xiangyi Ding, ${ }^{2}$ and Jingying Fu ${ }^{1}$ \\ ${ }^{1}$ Institute of Geographical Sciences and Natural Resources Research, Chinese Academy of Sciences, Beijing 100101, China \\ ${ }^{2}$ State Key Laboratory of Simulation and Regulation of Water Cycle in River Basin, Department of Water Resources, \\ China Institute of Hydropower \& Water Resources Research, Beijing 100038, China \\ ${ }^{3}$ Computer Network Information Center, Chinese Academy of Sciences, Beijing 100190, China
}

Correspondence should be addressed to Jianhua Wang; wjh@iwhr.com and Yaohuan Huang; huangyh@lreis.ac.cn

Received 14 February 2014; Revised 13 May 2014; Accepted 20 May 2014; Published 5 June 2014

Academic Editor: Dawei Han

Copyright (C) 2014 Dong Jiang et al. This is an open access article distributed under the Creative Commons Attribution License, which permits unrestricted use, distribution, and reproduction in any medium, provided the original work is properly cited.

\begin{abstract}
The Gravity Recovery and Climate Experiment (GRACE) satellite provides a new method for terrestrial hydrology research, which can be used for improving the monitoring result of the spatial and temporal changes of water cycle at large scale quickly. The paper presents a review of recent applications of GRACE data in terrestrial hydrology monitoring. Firstly, the scientific GRACE dataset is briefly introduced. Recently main applications of GRACE data in terrestrial hydrological monitoring at large scale, including terrestrial water storage change evaluation, hydrological components of groundwater and evapotranspiration (ET) retrieving, droughts analysis, and glacier response of global change, are described. Both advantages and limitations of GRACE data applications are then discussed. Recommendations for further research of the terrestrial water monitoring based on GRACE data are also proposed.
\end{abstract}

\section{Introduction}

Intensified impact of human activities and global change inevitably lead to the changes in the water cycle, including the spatial and temporal distribution and the total amount of water resources $[1,2]$. Terrestrial hydrology, which is an important indicator in global change, affects the global climate system in energy, water, and biogeochemical [3]. Traditional monitoring of terrestrial hydrology mainly depends on site measurements or model simulations, which is costly and time-consuming. Furthermore, for the scale effects of the conversion from observation points to large region, additional error will be brought into spatially continuous data obtained by statistical interpolation methods. The accuracy of interpolation results may significantly decrease in areas far away from observation sites. Hydrological models and land surface models solve the problem of simulation of terrestrial hydrology on the plane scale to some degree. However, the lack of systematic global fine-scale hydrological data increases the model uncertainty and lowers the simulation accuracy. This restricts the practical application of hydrological models and land surface models in the monitoring of terrestrial hydrology. With the rapid development of remote sensing technology, remote sensing holds significant potential to the regional hydrological researches. By offering a useful and cost-effective approach to rapidly monitor terrestrial hydrological parameters, remote sensing technology has been widely used in hydrology. Recently, combination models of remote sensing technology, observation network, and hydrological models have been common in terrestrial hydrology studies. However, imaging satellite techniques and satellite altimetry can only be used in the monitoring of surface water that represents just one component of total water storage. They can be hardly applied in the monitoring of other components of terrestrial water such as soil water and groundwater, which impeded further applications of these technologies in terrestrial hydrology. 
Launched in March 2002, the Gravity Recovery and Climate Experiment (GRACE) can provide an operational product in the form of global gravity fields every $~ 30$ days [4]. After several gravity effects have been released (e.g., atmospheric mass variations and ocean tides), precise observations of the time-series global gravity field changes make the spatial monitoring of water storage changes at large scale such as basins possible. Through 10 years of development, GRACE satellite data processing and corresponding TWS retrieval algorithms are improved continuously. They are able to detect the changes of TWS within the accuracy of $1.5 \mathrm{~cm}$ on a wide range of spatial scales and seasonal time scales [5]. Compared to imagery remote sensing methods, they provide alternative technical methods for the estimation of glaciers, surface snow, soil water, surface water, groundwater, evaporation, and other components in the terrestrial hydrological system. It provides a new technique for the large-scale monitoring of terrestrial water cycle. The objective of this paper is to present an overview of GRACE data applications in terrestrial hydrology monitoring, including GRACE data processing methods and TWS change retrieval and their application in terrestrial hydrology and related fields.

\section{GRACE Data}

GRACE gravity satellite program was jointly developed by the National Aeronautics and Space Administration (NASA) of the United States and the German Aerospace Center (DLR) with the objective of providing spatiotemporal variations of the Earth's gravity field. The GRACE satellite program can be also used to detect the atmosphere and ionosphere environment. The US Jet Propulsion Laboratory (JPL) is responsible for the project management of the GRACE gravity satellite program. Monthly gravity field solutions are computed at the University of Texas at Austin Center for Space Research (CSR), the German Research Centre for Geosciences Potsdam (GFZ), JPL, Groupe de Recherche de Geodesie Spatiale (GRGS), and the Delft Institute of Earth Observation and Space Systems (DEOS) as well as Delft University of Technology, among others [4, 6-8]. GRACE utilizes a state-of-the-art technique to trace the spatiotemporal gravity field with an increased sensitivity by tracking the micrometer-precise intersatellite range and range-rate observations between two coplanar, low altitude $(300 \mathrm{~km} \sim 500 \mathrm{~km})$ satellites and the distance between which is about $220 \mathrm{~km}$. To precisely measure the distance changes between two satellites at micron meter level accuracy, a K-band ranging (KBR) system based on carrier phase measurements in the K $(26 \mathrm{GHz})$ and $\mathrm{Ka}(32 \mathrm{GHz})$ frequencies is provided. Besides, four key instrumentations of a GPS receiver (space-proofed multichannel, two-frequency), capacitive accelerometer, laser retroreflector (LRR), and star camera are equipped on board of each GRACE satellite $[4,7]$.

By analyzing the relationship between orbits and forces of GRACE satellites, the Earth's gravity field variety is estimated based on the dynamic equations of satellites motion. It monitors the time-varying characteristics of long-wavelength gravity field on a 15 30-day or longer time scale. Large-scale mass redistribution (mass distribution changes over time) in the Earth system reflects the interaction between substances of various forms in the Earth's internal system (atmosphere, oceans and solid crust, viscous mantle, liquid outer core, and solid inner core), which are the important subjects of Earth sciences. Compared to the average Earth's gravity field, the time-varying quantity of the gravity field is very small, but it contains important geophysical information. It reveals the movement, distribution, and changes of all substances in the Earth system and reflects the interaction between the atmosphere, terrestrial water, oceans, and the solid Earth [6].

The time variation of global gravity field caused by the influence of solid Earth (including the inner core and the outer core) is mainly manifested on a 10 -year or a longer time scale. However, temporal variation of gravity is mainly caused by the redistribution influence of atmosphere, oceans, and water storages in the surface fluid envelopes of the earth on a seasonal or interannual time scale $[9,10]$. The gravity effects of tides (solid Earth, oceans, and atmosphere) and nontidal (atmosphere and oceans) are reduced in the data processing of GRACE gravity field model. Therefore, by excluding the errors in gravity field model and the atmosphere and oceans models, GRACE time-varying gravity field reflects the nonatmospheric and nonocean mass variations due to water mass variations on the continental area. On a seasonal or shorter time scale, it provides information on changes in terrestrial water storage in large river basin [11].

\section{Hydrological Applications}

3.1. TWS Changes Monitoring. The TWS is the most direct hydrological parameter obtained by GRACE monitoring. For the main goal of GRACE satellite is to monitor the Earth's gravity field variations, early researches are focused on the feasibility and accuracy of TWS retrieval from GRACE data. Wahr et al. [11] pointed out that the GRACE-based TWS retrieval required the consideration of the impacts from short-wave noises and leakage errors, and the TWS retrieval result is valid for large-scale river basins. Further research of Rodell and Famiglietti showed that TWS accuracy could be improved by increasing the monitoring temporal interval and spatial resolution of the monitored area $[12,13]$. For regions larger than $200000 \mathrm{~km}^{2}$, the TWS changes with intervals on month and longer time scale can be monitored, and the accuracy can reach $1.5 \mathrm{~cm}$ and above.

The application of GRACE-based TWS changes data is mainly based on the combination of hydrological models and land surface models. GRACE-based TWS retrieval results offer spatial and temporal distribution of vertically integrated water storage (surface water, soil, groundwater, and snowpack) in large river basins. So the errors due to the use of indirect indicators such as the flow rate and precipitation in some hydrological models can be reduced. In initial researches, the GRACE-based TWS is only considered as a reference to the simulation results from hydrological models (such as GDLAS and CPC), which does not involve the uncertainty of hydrological models in the simulation process. Hu et al. [10] proposed that water storage changes in 
Yangtze River could reach a magnitude of $3.4 \mathrm{~cm}$ equivalent water height, with the maximum occurring in the spring and early autumn. Using 5-year GRACE-based TWS change data in China, Zhong et al. [14] pointed out that the water storage in the north-central region of China diminished at an annual rate of $2.4 \mathrm{~cm}$ water equivalent height. By combining GRACE and GPS network observation data, Wang et al. [15] achieved precise retrieval of TWS change in Nordic region and North America. Their studies showed that, over the past decade, a sharp increase appeared in the water storage in North America and Scandinavia and a water recovery process is underway.

With further study, GRACE data is now considered as an important parameter to assess and improve hydrological model simulation. Swenson and Milly [16] and Syed et al. [17] used GRACE data to verify and improve TWS simulation of five climate models and the Global Land Data Assimilation System (GLDAS), respectively. Niu and Yang [18] and NgoDuc et al. [19] used GRACE data for the result verification of common land surface model (CLM) of NCAR and ORCHIDEE and corrected the CLM by applying GRACEbased TWS changes data.

Various quantitative analyses between hydrological models and GRACE-based TWS showed that the two simulation results of large areas are in good consistency on a seasonal or longer time scale $[16,20,21]$. Time-series analyses of South and North America, Southeast Asia, the Ganges River Basin, Africa, Eurasia, and other large-scale regions all showed that GRACE-based TWS reflected a significant seasonal variation. However, given the limitations in the spatial resolution of GRACE data, the consistency of hydrological models and GRACE data in smaller areas is not satisfactory [22]. Excluding the errors of GRACEbased TWS change retrieval, the inconsistency is mainly due to the simulation errors of various TWS components from hydrological models. For example, the generalized deviation in estimating the important elements such as groundwater, surface water, and soil water storage by using hydrological models resulted in smaller magnitudes in TWS changes. The errors in the simulation of rainfall, convergence, and other hydrological processes generated phase deviation in TWS changes time series $[17,23,24]$. In addition, by combination of the measured data of rainfall, recharge, soil water, and groundwater, GRACE-based TWS was used for water storage variation of basin on interannual, annual, seasonal, and monthly time scales $[25,26]$.

3.2. Hydrological Components Evaluation. With the improvement of GRACE-based TWS change accuracy, the GRACE data is further used in hydrology and water resources research. For specific areas, TWS changes can be expressed as [10]

$$
\frac{d W}{d t}=P-E-R,
$$

where $d W / d t$ represents TWS changes, and the corresponding equivalent water height can be obtained from GRACE. $P$ represents precipitation, $E$ represents evapotranspiration, and $R$ represents surface runoff. By combining GRACE-based TWS changes, hydrological models, and the measured data, the water storage components including groundwater, soil water, ET, and $P-E$ can be estimated, respectively.

Groundwater estimation is difficult in remote sensing applications in hydrology. Optical remote sensing methods can only combine measured data with spectral data to construct an empirical model for the estimation of groundwater changes, whose groundwater retrieval accuracy is poor. Considering the contribution of groundwater changes to TWS variation, groundwater remote sensing using GRACE was feasible by combination with ancillary measurements of surface waters and soil moisture. Rodell and Famiglietti [27] firstly used GRACE-based TWS change data, soil water, and other auxiliary data to analyze the possibility of monitoring groundwater changes. Swenson et al. [25] studied the relation between measured value of groundwater plus soil water and GRACE-based TWS changes and presented the possibility and sources of error in groundwater estimation based on GRACE data on multiple time scales. Strassberg et al. [28] compared the spatiotemporal correlation between GRACEbased TWS changes and hydrological model simulations and field monitoring data and proposed the uncertainty of GRACE-based groundwater retrieval. The above studies suggest that, for aquifers larger than $450000 \mathrm{~km}^{2}$, the accuracy of GRACE-based groundwater can reach $8.7 \mathrm{~mm}$. Rodell et al. applied GRACE data to the groundwater subsidence monitoring in India and found that excessive irrigation and human activities caused the groundwater in the northwest provinces of India to decline at an annual rate of $3.0 \mathrm{~cm} \sim$ $4.0 \mathrm{~cm}[29]$.

Evapotranspiration (ET) is an important process parameter to studies of hydrology, which is difficult to measure at a regional or continental scale. Although ET can be indirectly estimated using remote sensing data based on empirical models, energy balance models, or physical models (e.g., PenmanMonteith equation), recent remote-sensed ET estimation is far from satisfactory [30]. For ET is a complex process that related to many variables, its estimation uncertainty based on remote sensing data brings errors to ET retrieval results. Based on terrestrial water balance at scale of river basin, changes of regional ET can be estimated by combining TWS change from GRACE with observed precipitation $(P)$ and runoff data $(R)$. Rodell et al. [31] first used the measured precipitation and runoff data to verify the feasibility of GRACE-based ET retrieval. However, the overdependence on measured data restricts the applicability of this method. Therefore, Ramillien et al. [32] improved this algorithm by using the simulated runoff data from hydrological model. The time-series analysis showed that the ET estimation and WGHM simulation were in good consistency. However, uncertainty of GRACE-based ET estimation increases for its overdependence on accuracy of hydrological model simulated variables such as runoff. In addition, Swenson and Wahr [33] combined GRACE-based TWS changes together with the measured runoff data to estimate the difference between precipitation and evapotranspiration $(P-E)$. By comparing with $P-E$ results of a land surface model (GLDAS-Noah), 
they found that the errors of GLDAS-Noah estimation are mainly due to model force parameter of precipitation.

3.3. Drought Analysis. Based on time-series analysis of GRACE-based TWS change with high temporal resolution, extreme hydrological disasters can be monitored and alarmed. Droughts for regional and time-series water storage deficit are the most serious natural hazards that can lead to crop losses and economic havoc in many areas. For droughts can be regarded as terrestrial water storage (TWS) changes that are related to integrated bulk variables, analysis relying upon subcomponents (e.g., precipitation) or proxies (e.g., NDVI and CWSI) of TWS is insufficient. Herewith, another hydrological application of GRACE is severe droughts analysis. Combined with the measurements and hydrological model simulations, Leblanc et al. [34] used GRACE data to detect droughts in Southeastern Australia between 2001 and 2008. Based on time-series analysis of TWS changes in summers from 2002 to 2007, 2005 extreme drought event in the Amazon river basin was detected [35], which was regarded as the worst in over a century. GRACE data is more sensitive to droughts than data-assimilating climate and land surface models such as NECEP and GLDAS, which demonstrated the unique potential of GRACE in monitoring largescale severe drought events. Validated by two independent hydrological estimates of GLDAS and ECMWF and direct gravity observations from superconducting gravimeters, the 2003 excess terrestrial water storage depletion was observed from GRACE, which can be related to the record-breaking heat wave that occurred in central Europe in 2003 [36]. It indicated that GRACE data can be used in heat wave disaster monitoring and evaluation, whose essence is heat wave caused droughts analysis. Combining with imagery remote sensing methods, Frappart and Wilson et al. applied GRACE data to flood monitoring in several flood zones such as the Mekong River Basin and the Amazon River Basin $[37,38]$. However, compared to droughts, the water storage changes based on GRACE data of extreme floods are less responsive, which will bring more uncertainty in GRACEbased floods analysis [39].

3.4. Glacier Mass Balance Detection. Driven by global change and population pressure, accelerating of glaciers melting and sea level rise has been a serious global ecological problem. GRACE time-variable gravity field enabled direct measurement of mass loss rates of both mountain glacier and polar glacier systems. As noted by Wouters et al. the GRACE solutions can be used to allow regional estimation of trends, though assessing the mass loss to be dominated by summer events rather than by a linear trend [40]. GRACEbased glacier mass melting volume and rate estimation of Antarctic and Greenland indicate that accelerating polar glacier melting contributes greatly to the current eustatic sea level rise [41-43]. Gardner et al. have also found a rapidly increasing mass loss in the Canadian Arctic Archipelago (CAA) for the period 2004-2009 [44]. Ice loss rate estimation on glaciers of Asia, Alaska, and other global mountains based on GRACE data also agrees with the global tendency of accelerating glacial loss. Accelerated melting of mountain glaciers worldwide might be contributing to the global sea level rise by $0.73 \pm 0.10 \mathrm{~mm} / \mathrm{yr}[45,46]$. Moreover, GRACEbased TWS change can be used for researches of different climate variability impact $[47,48]$ whereas, for the postglacial rebound effects and unique set of gravity data GRACE mission provided, ice sheet mass change estimation includes large uncertainties [49]. Mass change rates estimated by different GRACE solutions may vary by a factor of two or more. So the glacier mass balance detection needs considerable processing to yield usable mass change data [49].

\section{Discussion and Conclusions}

Through ten years of development, GRACE data has been widely applied in terrestrial hydrology monitoring. Gravity satellite provides new data sets for hydrology researches based on remote sensing technology. Compared with other kinds of hydrological schemes, GRACE can provide realistic spatiotemporal variations of vertically integrated measurement of water storage (groundwater, soil moisture, surface water, snow water, vegetation water, etc.) at the precision of tens of $\mathrm{mm}$ of equivalent water height at large scale. However, the hydrological monitoring based on GRACE data needs further research, for example, retrieval accuracy improvement, more quantitative analyses rather than qualitative analyses, and so forth. The focus of future development includes the following aspects.

(1) Improving the Accuracy of Gravity Satellite Measurements. Because of the limitations of GRACE satellite sensors in orbital altitude, vertical gravity gradient measurements, high frequency signal aliasing, and accurate measurement of timevarying gravity signals, the accuracy and spatial resolution of time-varying Earth gravity field signals at medium and long wavelength of GRACE is low, which reduced the TWS change retrieval accuracy. Therefore, the development of key technology in gravity satellite sensors to improve accuracy and spatial resolution of satellite monitored gravity field is the basis for a wider application in terrestrial hydrology monitoring.

(2) Water Storage Retrieval Models Research. Recently, the appropriate spatial resolution for GRACE-based TWS change is $400 \mathrm{~km}$, and the data accuracy is generally $1.5 \mathrm{~cm}$. Limited by recent constraints of GRACE satellite, improvement of retrieval models is the only method for spatial resolution and accuracy retrieval of TWS increases. For example, it is feasible to improve TWS accuracy by the atmosphere and ocean models improvement in data preprocessing, reducing the gravity field changes noises caused by factors unrelated to terrestrial water such as tides and circulation of atmosphere and ocean. In addition, by applying different filtering methods such as anisotropic Gaussian filtering and spherical radial basis function filtering, wavelet analysis in different research areas can also improve the spatial resolution and accuracy of TWS retrieval. Water storage retrieval techniques involve various aspects (e.g., GRACE data preprocessing, gravity field retrieval, and TWS changes estimation) of the conversion 
of GRACE gravity field data to TWS changes, which are all important in TWS retrieval improvement.

(3) Further Combination of GRACE Data with Associated Hydrological Models. For GRACE-based TWS changes retrieval does not involve the hydrological mechanisms, it is necessary to complement GRACE-based TWS by hydrological models for furthering its application in terrestrial hydrology monitoring. Further combination of GRACE and hydrological models needs resolving their consistencies of space, time, and component. Spatial consistency can be solved by adjusting the calculation unit of hydrological models to reflect the spatial variability (such as distributed hydrological models). Temporal consistency requires analysis of upscaling GRACE data and downscaling hydrological models simulation. Component consistency can be achieved by GRACEbased TWS signals subdivision or revising parameters of hydrological models to TWS. Through space, time, and component consistency improvement, the gravity field data and measured data together can become basic dataset to force hydrological models in the future.

\section{Appendices}

\section{A. Water Storage Change Retrieval}

The changes in terrestrial water storage result in mass redistribution in the Earth's system, thereby causing changes in the gravity field. For a fixed continental region, the changes in water storage (including soil water and surface snow) come from rainfall, evapotranspiration, river transportation, and deep underground infiltration. Except the rainfall which can cause increased water storage, the remaining three processes all reduce it [10]. Using the FG5 absolute gravimeter, Zhang et al. [50] measured the gravity change of nearly $10^{-7} \mathrm{~m} \cdot \mathrm{s}^{-2}$ at the Wuhan University site before and after a rainstorm, which clearly shows the influence of terrestrial water variation on gravity. The Earth's gravity field can be expressed as geoid:

$$
\begin{aligned}
& N(\theta, \lambda) \\
& \quad=a \sum_{n=0}^{\infty} \sum_{m=0}^{n}\left[\bar{C}_{n m} \cos (m \lambda)+\bar{S}_{n m} \sin (m \lambda)\right] \bar{P}_{n m}(\cos \theta)
\end{aligned}
$$

where $n$ and $m$ are harmonic degree and order of the gravity field, respectively; $a$ is the Earth's equatorial radius (about $6,371 \mathrm{~km}$ ); $\theta$ and $\lambda$ are colatitudes (the difference between $90^{\circ}$ and latitude) and longitude; $\bar{C}_{n m}$ and $\bar{S}_{n m}$ are spherical harmonic coefficients (dimensionless); $\bar{P}_{n m}$ is the normalized associated Legendre functions. The maximum value $N$ of the order $n$ of ideal gravity field should be infinite $(N \sim$ $\infty)$, while the actual order of spherical harmonic coefficients obtained by the gravity satellite has a finite value $(N<\infty)$ and the spatial resolution of gravity field data is estimated approximately to be $\pi a / N[51]$. Geoid height changes $\Delta N$ caused by the movement of substances on the Earth's surface can be expressed as

$$
\begin{aligned}
& \Delta N(\theta, \lambda) \\
& \quad=a \sum_{n=0}^{\infty} \sum_{m=0}^{n}\left[\Delta \bar{C}_{n m} \cos (m \lambda)+\Delta \bar{S}_{n m} \sin (m \lambda)\right] \bar{P}_{n m}(\cos \theta),
\end{aligned}
$$

where $\Delta \bar{C}_{n m}$ and $\Delta \bar{S}_{n m}$ are the changes of $n$-degree $m$-order spherical harmonic coefficients of geoid and can be expressed as $[5,52]$

$$
\begin{aligned}
& \left\{\begin{array}{c}
\Delta \bar{C}_{n m} \\
\Delta \bar{S}_{n m}
\end{array}\right\} \\
& =\frac{3}{4 \pi a \rho_{a}(2 n+1)} \\
& \times \int \Delta \rho(r, \theta, \lambda) \bar{P}_{n m}(\cos \theta)\left(\frac{r}{a}\right)^{n+2}\left\{\begin{array}{l}
\cos (m \lambda) \\
\sin (m \lambda)
\end{array}\right\} \sin \theta d \theta d \lambda d r,
\end{aligned}
$$

where $\rho_{a}$ is the average density of the Earth $\left(5517 \mathrm{~kg} / \mathrm{m}^{3}\right)$ and $\Delta \rho(r, \theta, \lambda)$ is the change of bulk density at a particular location. In gravity field inversion, because the height change of substances on the Earth's surface $H$ is relatively small compared to the Earth's average radius $a$ in gravity field retrieval $((r / a) \approx 1)$, the changes of the gravity field directly caused by the surface mass can be expressed as

$$
\begin{aligned}
& \left\{\begin{array}{c}
\Delta \bar{C}_{n m} \\
\Delta \bar{S}_{n m}
\end{array}\right\}_{\text {surf }} \\
& =\frac{3}{4 \pi a \rho_{a}(2 n+1)} \\
& \quad \times \int \Delta \sigma(\theta, \lambda) \bar{P}_{n m}(\cos \theta)\left\{\begin{array}{c}
\cos (m \lambda) \\
\sin (m \lambda)
\end{array}\right\} \sin \theta d \theta d \lambda,
\end{aligned}
$$

where $\Delta \sigma$ is surface density change $\Delta \sigma=\int \Delta \rho(r, \theta, \lambda) d r$. Furthermore, the surface mass variation in loads will cause deformation to the solid Earth, which in turn can indirectly cause variations to the gravity field. This can be expressed as $[5,52]$

$$
\begin{aligned}
& \left\{\begin{array}{c}
\Delta \bar{C}_{n m} \\
\Delta \bar{S}_{n m}
\end{array}\right\}_{\text {soild }} \\
& =\frac{3 k_{n}^{\prime}}{4 \pi a \rho_{a}(2 n+1)} \\
& \quad \times \int \Delta \sigma(\theta, \lambda) \bar{P}_{n m}(\cos \theta)\left\{\begin{array}{l}
\cos (m \lambda) \\
\sin (m \lambda)
\end{array}\right\} \sin \theta d \theta d \lambda,
\end{aligned}
$$

where $k_{n}^{\prime}$ is load LOVE number of coefficients, and the specific value of $k_{n}^{\prime}$ can be found in relevant literature [11]. 
Thus, the change of the Earth's gravity field caused by mass variations on the Earth's surface is given by

$$
\begin{aligned}
\left\{\begin{array}{c}
\Delta \bar{C}_{n m} \\
\Delta \bar{S}_{n m}
\end{array}\right\} & =\left\{\begin{array}{c}
\Delta \bar{C}_{n m} \\
\Delta \bar{S}_{n m}
\end{array}\right\}_{\text {surf }}+\left\{\begin{array}{c}
\Delta \bar{C}_{n m} \\
\Delta \bar{S}_{n m}
\end{array}\right\}_{\text {soild }} \\
& =\left(1+k_{n}^{\prime}\right)\left\{\begin{array}{c}
\Delta \bar{C}_{n m} \\
\Delta \bar{S}_{n m}
\end{array}\right\}_{\text {surf }} .
\end{aligned}
$$

If the spherical harmonic expansion is performed on the surface density change $\Delta \sigma$, then

$$
\begin{aligned}
& \Delta \sigma(\theta, \lambda) \\
& =a \rho_{w} \sum_{n=0}^{\infty} \sum_{m=0}^{n}\left[\widehat{C}_{n m} \cos (m \lambda)+\widehat{S}_{n m} \sin (m \lambda)\right] \bar{P}_{n m}(\cos \theta)
\end{aligned}
$$

where $\rho_{w}$ is the density of water and $\Delta \sigma / \rho_{w}$ can be considered as mass variation on the Earth's surface expressed in water equivalent height. Wahr et al. [5] proposed that

$$
\left\{\begin{array}{c}
\Delta \widehat{C}_{n m} \\
\Delta \widehat{S}_{n m}
\end{array}\right\}=\frac{\rho_{a}}{3 \rho_{w}} \frac{2 n+1}{1+k_{n}^{\prime}}\left\{\begin{array}{c}
\Delta \bar{C}_{n m} \\
\Delta \bar{S}_{n m}
\end{array}\right\} .
$$

The surface density change $\Delta \sigma$ can be calculated using the following equation:

$$
\begin{aligned}
& \Delta \sigma(\theta, \lambda) \\
& =\frac{a \rho_{a}}{3} \sum_{n=0}^{\infty} \sum_{m=0}^{n} \frac{2 n+1}{1+k_{n}^{\prime}}\left[\bar{C}_{n m} \cos (m \lambda)+\bar{S}_{n m} \sin (m \lambda)\right] \\
& \quad \times \bar{P}_{n m}(\cos \theta) .
\end{aligned}
$$

For ocean and atmosphere mass variations are removed based on Parallel Ocean Program (POP) model, the above equation is the basic equation for the retrieval of surface mass variations based on spatiotemporal changes gravity field. The Earth's surface density changes can be derived from the changes of gravity field coefficients obtained from GRACE satellites.

\section{B. Evaluation Errors}

Currently, the latest available GRACE dataset product is the RL05. The accuracy of data provided by CSR and GFZ is better than that provided by JPL. The evaluation errors of GRACE are brought from satellite instruments measurement, retrieval models, and other factors as follows.

(1) Gravity field data measured by GRACE satellite may be contaminated by satellite measurement errors for the influence of satellite orbit, satellite K-band ranging, and accelerometer measurement [20]. The satellite measurement errors also include poor accuracy of C20 due to the insensitivity of track geometry to the gravity field's low degree gravitational variations $[5,20]$. It is generally released with removing variation of C20 [10] or replacing it by satellite laser ranging (SLR) substitution [20]. In addition, the missing of first-degree spherical harmonic coefficients will also bring error to GRACE. It can commonly be resolved by substituting value calculated from the term of the seasonal changes of the Earth's mass center $[53,54]$ or ignoring its impact [55].

(2) In theory, the retrieval of gravity field variation needs to use spherical harmonic coefficients of all degrees from 0 to infinity. However, gravity satellites can only provide definite order data. So the surface density change $\Delta \sigma$ in retrieval models is treated by spherical harmonic expansion to definite orders. For the impact of high-order terms on the Earth's surface density change $\Delta \sigma$ cannot be ignored, it results in truncation errors in gravity field retrieval. RL05 water storage data is estimated by CSR using a retrieval model truncated to degree 60 [8]. Zhu et al. (2008) compared the global water storage retrieval results using models truncated to 15 degrees, 20 degrees, 35 degrees, and 60 degrees [56]. They found that although some information of TWS change may be missing the retrieval result of TWS change became more marked with lower truncation degree. Generally, the water storage retrieval truncated to order 60 is widely adopted [17].

(3) For terrestrial water monitoring focusing on the mass changes of a particular area (e.g., river basin), it requires the integral process on density change $\Delta \bar{\sigma}=\left(\left(\int \Delta \sigma(\theta, \lambda) u(\theta, \lambda) d \Omega\right) / \Omega\right)$. The function of regional characteristics $u(\theta, \lambda)$ is equal to 1 inside the particular area and to zero outside. The error will be brought for the discontinuity of $u(\theta, \lambda)$ in the domain of integration. In addition, for the influence of rapid increase of the errors of GRACE gravity field model coefficients with increase of spherical harmonic coefficients degree, signal leakage errors, and the striping pollution [23], filtering methods are proposed to smooth GRACE data for noise reducing, which will result in filtering errors of retrieval results. Proposed filtering methods include spatial averaging, symmetric Gaussian filtering, optimized decorrelation filtering, time-series method, global hydrological model correction method, kernel-independent component analysis, and optimal smoothing kernel method [53, 57-62]. Using filtering for the integral treatment of surface density changes can effectively remove the striping to a certain extent. However, the obtained average surface density is critical for it reduces the useful energy of geophysical signals and results in filtering errors. In addition, the existing filtering methods require the support of a priori knowledge (such as filtering radius and truncation degree). Therefore, in the actual retrieval process, the filter selection and parameter calibration require an understanding of the specific regional characteristics $[60,63]$. 
(4) TWS changes retrieval based on spatiotemporal variations of gravity field remains considerable uncertainty, which includes errors produced in the removal of tidal movement and the mass migration because of the atmosphere and ocean circulation [11], as well as the errors in hydrological models used for the estimation of other terrestrial water parameters [6].

\section{Conflict of Interests}

The authors declare that there is no conflict of interests regarding the publication of this paper.

\section{Acknowledgments}

This project was supported by National Natural Science Foundation of China (Grant no. 51309210) and the Chinese Academy of Sciences (Grant no. KZZD-EW-08).

\section{References}

[1] Y. Huang, D. Jiang, D. Zhuang, Y. Zhu, and J. Fu, "An improved approach for modeling spatial distribution of water use profita case study in Tuhai Majia Basin, China," Ecological Indicators, vol. 36, pp. 94-99, 2014.

[2] Y.-H. Huang, D. Jiang, D.-F. Zhuang, J.-H. Wang, H.-J. Yang, and H.-Y. Ren, "Evaluation of relative water use efficiency (RWUE) at a regional scale: a case study of Tuhai-Majia Basin, China," Water Science and Technology, vol. 66, no. 5, pp. 927933, 2012.

[3] J. S. Famiglietti, "Remote sensing of terrestrial water storage, soil moisture and surface waters," in The State of the Planet: Frontiers and Challenges in Geophysics, R. S. J. Sparks and C. J. Hawkesworth, Eds., pp. 197-207, 2004.

[4] B. D. Tapley, S. Bettadpur, M. Watkins, and C. Reigber, “The gravity recovery and climate experiment: mission overview and early results," Geophysical Research Letters, vol. 31, no. 9, Article ID L09607, 2004.

[5] J. Wahr, S. Swenson, V. Zlotnicki, and I. Velicogna, "Timevariable gravity from GRACE: first results," Geophysical Research Letters, vol. 31, no. 11, Article ID L11501, 2004.

[6] A. Güntner, "Improvement of global hydrological models using GRACE data," Surveys in Geophysics, vol. 29, no. 4-5, pp. 375397, 2008.

[7] G. Ramillien, J. S. Famiglietti, and J. Wahr, "Detection of continental hydrology and glaciology Signals from GRACE: a review," Surveys in Geophysics, vol. 29, no. 4-5, pp. 361-374, 2008.

[8] D. P. Chambers, "Converting 11 Release-04 Gravity Coefficients into Maps of Equivalent Water Thickness," 2007, http://gracetellus.jpl.nasa.gov/files/GRACE-dpc200711_RL04.pdf.

[9] M. Becker, W. LLovel, A. Cazenave, A. Güntner, and J.-F. Crétaux, "Recent hydrological behavior of the East African great lakes region inferred from GRACE, satellite altimetry and rainfall observations," Comptes Rendus Geoscience, vol. 342, no. 3, pp. 223-233, 2010.

[10] X. Hu, J. Chen, Y. Zhou, C. Huang, and X. Liao, "Seasonal water storage change of the Yangtze River basin detected by Grace," Science in China D, vol. 49, no. 5, pp. 483-491, 2006.

[11] J. Wahr, M. Molenaar, and F. Bryan, "Time variability of the Earth's gravity field: hydrological and oceanic effects and their possible detection using GRACE," Journal of Geophysical Research B, vol. 103, no. 12, pp. 30205-30229, 1998.

[12] M. Rodell and J. S. Famiglietti, "Detectability of variations in continental water storage from satellite observations of the time dependent gravity field," Water Resources Research, vol. 35, no. 9, pp. 2705-2723, 1999.

[13] M. Rodell and J. S. Famiglietti, "An analysis of terrestrial water storage variations in Illinois with implications for the Gravity Recovery and Climate Experiment (GRACE)," Water Resources Research, vol. 37, no. 5, pp. 1327-1339, 2001.

[14] M. Zhong, J. Duan, H. Xu, P. Peng, H. Yan, and Y. Zhu, "Trend of China land water storage redistribution at mediand large-spatial scales in recent five years by satellite gravity observations," Chinese Science Bulletin, vol. 54, no. 5, pp. 816821, 2009.

[15] H. Wang, L. Jia, H. Steffen et al., "Increased water storage in North America and Scandinavia from GRACE gravity data," Nature Geoscience, vol. 6, no. 1, pp. 38-42, 2013.

[16] S. C. Swenson and P. C. D. Milly, "Climate model biases in seasonally of continental water storage revealed by satellite gravimetry," Water Resources Research, vol. 42, no. 3, Article ID W03201, 2006.

[17] T. H. Syed, J. S. Famiglietti, M. Rodell, J. Chen, and C. R. Wilson, "Analysis of terrestrial water storage changes from GRACE and GLDAS," Water Resources Research, vol. 44, no. 2, Article ID W02433, 2008

[18] G.-Y. Niu and Z.-L. Yang, "Assessing a land surface model's improvements with GRACE estimates," Geophysical Research Letters, vol. 33, no. 7, Article ID L07401, 2006.

[19] T. Ngo-Duc, K. Laval, G. Ramillien, J. Polcher, and A. Cazenave, "Validation of the land water storage simulated by Organising Carbon and Hydrology in Dynamic Ecosystems (ORCHIDEE) with Gravity Recovery and Climate Experiment (GRACE) data," Water Resources Research, vol. 43, no. 4, Article ID W04427, 2007.

[20] J. L. Chen, C. R. Wilson, B. D. Tapley, and J. C. Ries, "Low degree gravitational changes from GRACE: validation and interpretation," Geophysical Research Letters, vol. 31, no. 22, Article ID L22607, pp. 1-5, 2004.

[21] R. Klees, E. A. Revtova, B. C. Gunter et al., "The design of an optimal filter for monthly GRACE gravity models," Geophysical Journal International, vol. 175, no. 2, pp. 417-432, 2008.

[22] K.-W. Seo, C. R. Wilson, J. S. Famiglietti, J. L. Chen, and M. Rodell, "Terrestrial water mass load changes from Gravity Recovery and Climate Experiment (GRACE)," Water Resources Research, vol. 42, no. 5, Article ID W05417, 2006.

[23] B. D. Tapley, S. Bettadpur, J. C. Ries, P. F. Thompson, and M. M. Watkins, "GRACE measurements of mass variability in the Earth system," Science, vol. 305, no. 5683, pp. 503-505, 2004.

[24] D. P. Lettenmaier and J. S. Famiglietti, "Hydrology: water from on high," Nature, vol. 444, no. 7119, pp. 562-563, 2006.

[25] S. Swenson, P. J.-F. Yeh, J. Wahr, and J. Famiglietti, "A comparison of terrestrial water storage variations from GRACE with in situ measurements from Illinois," Geophysical Research Letters, vol. 33, no. 16, Article ID L16401, 2006.

[26] L. Xavier, M. Becker, A. Cazenave, L. Longuevergne, W. Llovel, and O. C. R. Filho, "Interannual variability in water storage over 2003-2008 in the Amazon Basin from GRACE space gravimetry, in situ river level and precipitation data," Remote Sensing of Environment, vol. 114, no. 8, pp. 1629-1637, 2010. 
[27] M. Rodell and J. S. Famiglietti, “The potential for satellite-based monitoring of groundwater storage changes using GRACE: the High Plains aquifer, Central US," Journal of Hydrology, vol. 263, no. 1-4, pp. 245-256, 2002.

[28] G. Strassberg, B. R. Scanlon, and M. Rodell, "Comparison of seasonal terrestrial water storage variations from GRACE with groundwater-level measurements from the High Plains Aquifer (USA)," Geophysical Research Letters, vol. 34, no. 14, Article ID L14402, 2007.

[29] M. Rodell, I. Velicogna, and J. S. Famiglietti, "Satellite-based estimates of groundwater depletion in India," Nature, vol. 460, no. 7258, pp. 999-1002, 2009.

[30] X. Lu and Q. Zhuang, "Evaluating evapotranspiration and water-use efficiency of terrestrial ecosystems in the conterminous United States using MODIS and AmeriFlux data," Remote Sensing of Environment, vol. 114, no. 9, pp. 1924-1939, 2010.

[31] M. Rodell, J. S. Famiglietti, J. Chen et al., "Basin scale estimates of evapotranspiration using GRACE and other observations," Geophysical Research Letters, vol. 31, no. 20, Article ID L20504, 2004.

[32] G. Ramillien, F. Frappart, A. Güntner, T. Ngo-Duc, A. Cazenave, and K. Laval, "Time variations of the regional evapotranspiration rate from Gravity Recovery and Climate Experiment (GRACE) satellite gravimetry," Water Resources Research, vol. 42, no. 10, Article ID W10403, 2006.

[33] S. Swenson and J. Wahr, "Estimating large-scale precipitation minus evapotranspiration from GRACE satellite gravity measurements," Journal of Hydrometeorology, vol. 7, no. 2, pp. 252270, 2006.

[34] M. Leblanc, P. Tregoning, G. Ramillien, S. O. Tweed, and A. Fakes, "Basin-scale, integrated observations of the early 21st century multiyear drought in southeast Australia," Water Resources Research, vol. 45, no. 4, Article ID W04408, 2009.

[35] J. L. Chen, C. R. Wilson, B. D. Tapley, Z. L. Yang, and G. Y. Niu, "2005 drought event in the Amazon River basin as measured by GRACE and estimated by climate models," Journal of Geophysical Research B, vol. 114, no. 5, Article ID B05404, 2009.

[36] O. B. Andersen, S. I. Seneviratne, J. Hinderer, and P. Viterbo, "GRACE-derived terrestrial water storage depletion associated with the 2003 European heat wave," Geophysical Research Letters, vol. 32, no. 18, Article ID L18405, pp. 1-4, 2005.

[37] F. Frappart, K. Do Minh, J. L'Hermitte et al., "Water volume change in the lower Mekong from satellite altimetry and imagery data," Geophysical Journal International, vol. 167, no. 2, pp. 570-584, 2006.

[38] M. D. Wilson, P. Bates, D. Alsdorf et al., "Modeling largescale inundation of Amazonian seasonally flooded wetlands," Geophysical Research Letters, vol. 34, no. 15, Article ID L15404, 2007.

[39] S.-C. Han, C. K. Shum, C. Jekeli, and D. Alsdorf, "Improved estimation of terrestrial water storage changes from GRACE," Geophysical Research Letters, vol. 32, no. 7, Article ID L07302, pp. 1-5, 2005.

[40] B. Wouters, D. Chambers, and E. J. O. Schrama, "GRACE observes small-scale mass loss in Greenland," Geophysical Research Letters, vol. 35, no. 20, Article ID L20501, 2008.

[41] I. Velicogna and J. Wahr, "Measurements of time-variable gravity show mass loss in Antarctica," Science, vol. 311, no. 5768, pp. 1754-1756, 2006.

[42] D. C. Slobbe, P. Ditmar, and R. C. Lindenbergh, "Estimating the rates of mass change, ice volume change and snow volume change in Greenland from ICESat and GRACE data," Geophysical Journal International, vol. 176, no. 1, pp. 95-106, 2009.

[43] P. L. Svendsen, O. B. Andersen, and A. A. Nielsen, "Acceleration of the Greenland ice sheet mass loss as observed by GRACE: confidence and sensitivity," Earth and Planetary Science Letters, vol. 364, pp. 24-29, 2013.

[44] A. S. Gardner, G. Moholdt, B. Wouters et al., "Sharply increased mass loss from glaciers and ice caps in the Canadian Arctic Archipelago," Nature, vol. 473, no. 7347, pp. 357-360, 2011.

[45] J. L. Chen, B. D. Tapley, and C. R. Wilson, "Alaskan mountain glacial melting observed by satellite gravimetry," Earth and Planetary Science Letters, vol. 248, no. 1-2, pp. 353-363, 2006.

[46] K. Matsuo and K. Heki, "Time-variable ice loss in Asian high mountains from satellite gravimetry," Earth and Planetary Science Letters, vol. 290, no. 1-2, pp. 30-36, 2010.

[47] D. García-García, C. C. Ummenhofer, and V. Zlotnicki, "Australian water mass variations from GRACE data linked to IndoPacific climate variability," Remote Sensing of Environment, vol. 115, no. 9, pp. 2175-2183, 2011.

[48] W. W. Immerzeel, L. P. H. van Beek, and M. F. P. Bierkens, "Climate change will affect the asian water towers," Science, vol. 328, no. 5984, pp. 1382-1385, 2010.

[49] L. S. Sørensen, S. B. Simonsen, K. Nielsen et al., "Mass balance of the Greenland ice sheet (2003-2008) from ICESat data-the impact of interpolation, sampling and firn density," Cryosphere, vol. 5, no. 1, pp. 173-186, 2011.

[50] W. Zhang, Y. Wang, and C. Zhang, "The preliminary analysis of effects of the soil moisture on gravity observations," Cartographica Sinica, vol. 30, no. 2, pp. 108-111, 2001.

[51] G. Ramillien, J. S. Famiglietti, and J. Wahr, "Detection of continental hydrology and glaciology signals from GRACE: a review," Surveys in Geophysics, vol. 29, no. 4-5, pp. 361-374, 2008.

[52] J. L. Chen, C. R. Wilson, R. J. Eanes, and B. D. Tapley, "Geophysical contributions to satellite nodal residual variation," Journal of Geophysical Research B, vol. 104, no. 10, pp. 2323723244, 1999.

[53] J. K. Willis, D. P. Chambers, and R. S. Nerem, "Assessing the globally averaged sea level budget on seasonal to interannual timescales," Journal of Geophysical Research C, vol. 113, no. 6, Article ID C06015, 2008.

[54] E. W. Leuliette and L. Miller, "Closing the sea level rise budget with altimetry, Argo, and Grace," Geophysical Research Letters, vol. 36, no. 4, Article ID L04608, 2009.

[55] J. L. Chen, C. R. Wilson, J. S. Famiglietti, and M. Rodell, “Attenuation effect on seasonal basin-scale water storage changes from GRACE time-variable gravity," Journal of Geodesy, vol. 81, no. 4, pp. 237-245, 2007.

[56] G. Zhu, J. Li, H. Wen, and J. Wang, "Study on variations of global continental water storage with GRACE gravity field models," Journal of Geodesy and Geodynamics, vol. 28, no. 5, pp. 39-44, 2008.

[57] S. Swenson and J. Wahr, "Methods for inferring regional surface-mass anomalies from Gravity Recovery and Climate Experiment (GRACE) measurements of time-variable gravity," Journal of Geophysical Research B, vol. 107, no. 9, pp. 3-1-3-13, 2002.

[58] S. Swenson and J. Wahr, "Monitoring changes in continental water storage with grace," Space Science Reviews, vol. 108, no. 1-2, pp. 345-354, 2003.

[59] K.-W. Seo and C. R. Wilson, "Simulated estimation of hydrological loads from GRACE," Journal of Geodesy, vol. 78, no. 7-8, pp. 442-456, 2005. 
[60] S. Swenson and J. Wahr, "Post-processing removal of correlated errors in GRACE data," Geophysical Research Letters, vol. 33, no. 8, Article ID L08402, 2006.

[61] G. Ramillien, F. Frappart, A. Cazenave, and A. Güntner, "Time variations of land water storage from an inversion of 2 years of GRACE geoids," Earth and Planetary Science Letters, vol. 235, no. 1-2, pp. 283-301, 2005.

[62] F. Frédéric, G. Ramillien, M. Leblanc et al., "An independent component analysis filtering approach for estimating continental hydrology in the GRACE gravity data," Remote Sensing of Environment, vol. 115, no. 1, pp. 187-204, 2011.

[63] S. Werth, A. Güntner, R. Schmidt, and J. Kusche, "Evaluation of GRACE filter tools from a hydrological perspective," Geophysical Journal International, vol. 179, no. 3, pp. 1499-1515, 2009. 

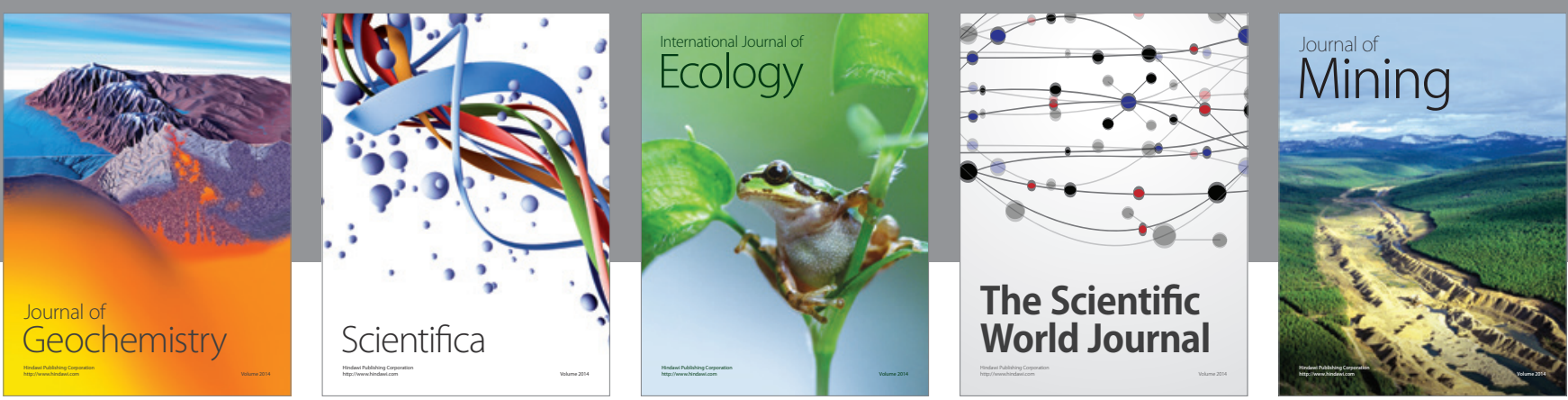

The Scientific World Journal
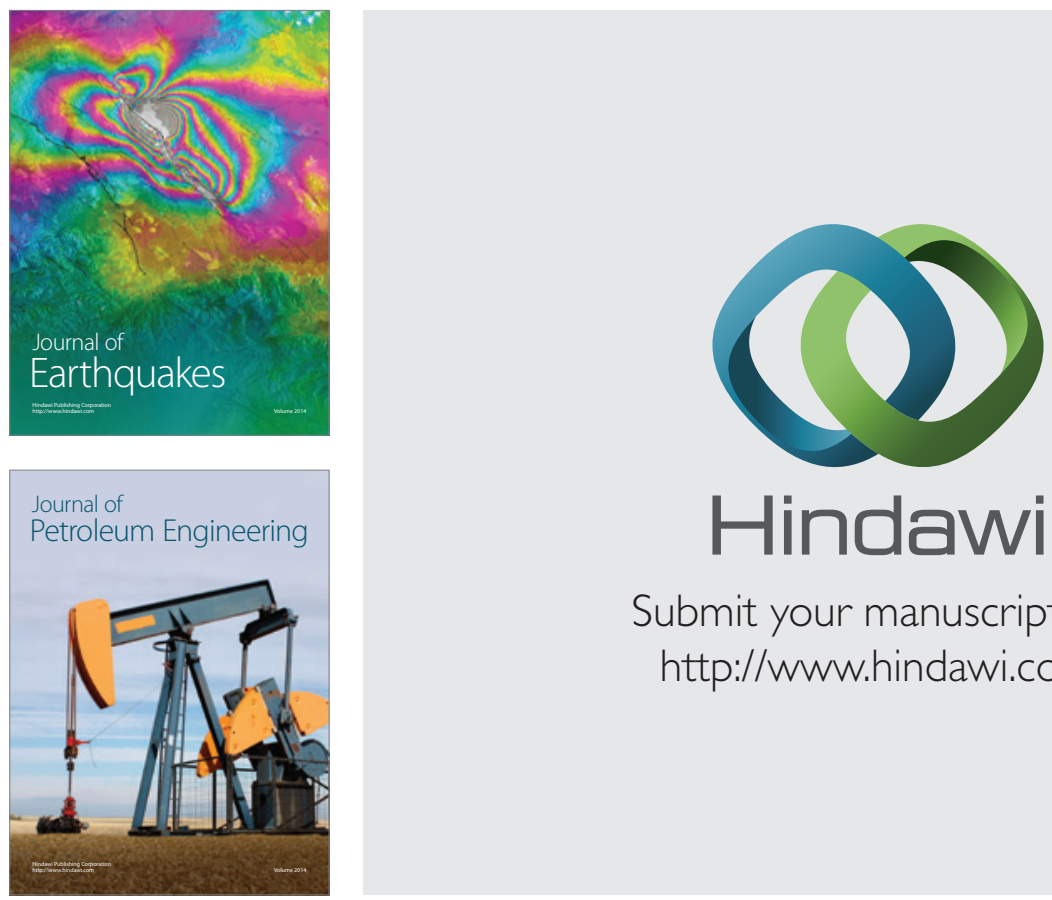

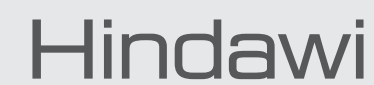

Submit your manuscripts at

http://www.hindawi.com
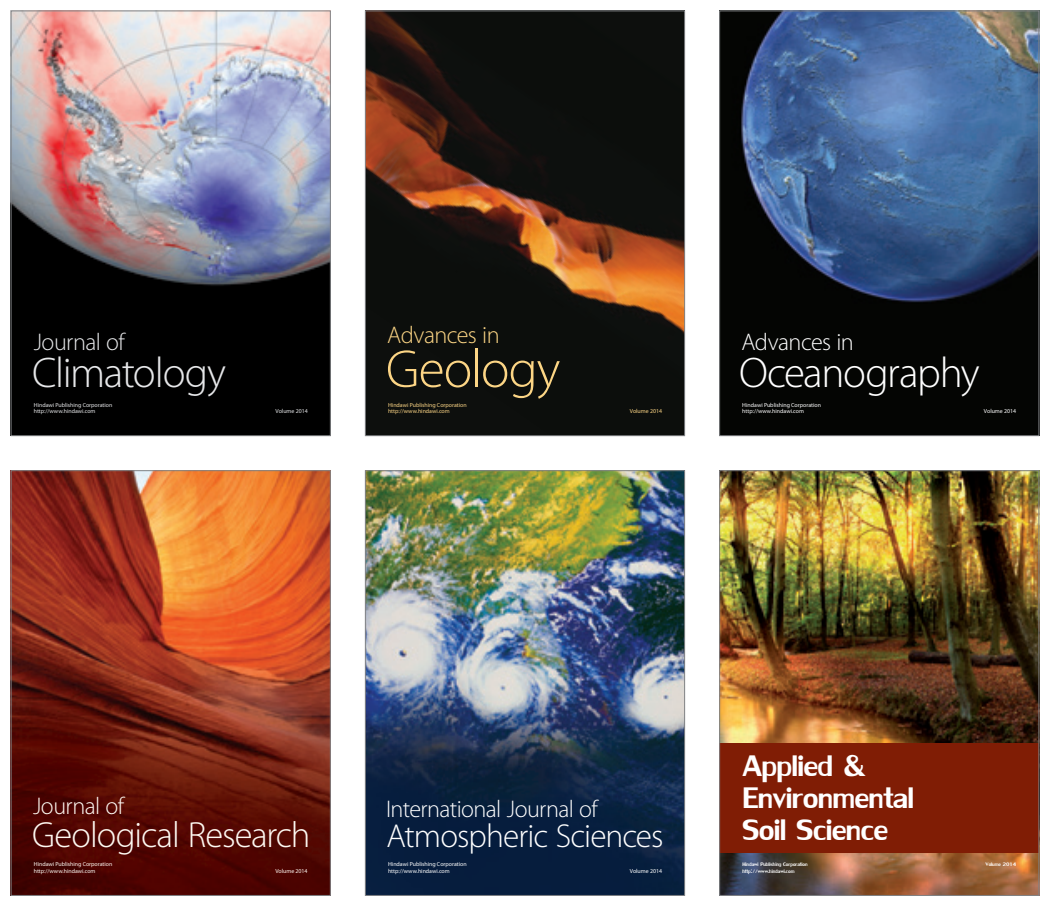
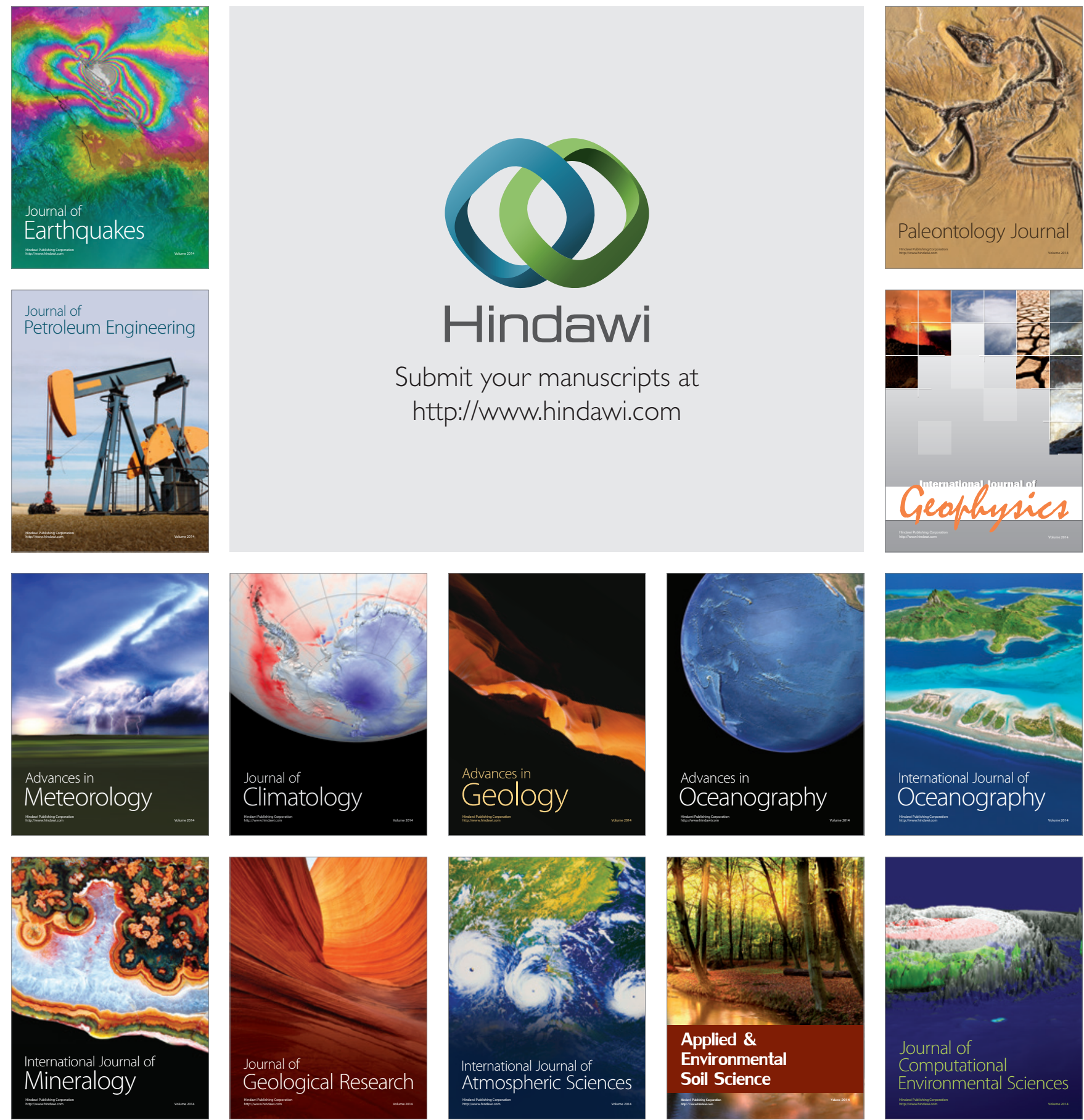